\title{
Biomarker-guided antifungal therapy in patients with suspected invasive candidiasis: Ready for prime time?
}

\author{
José-Artur Paiva ${ }^{1,2^{*}}$ and Pierre-Emmanuel Charles ${ }^{3}$
}

(C) 2017 Springer-Verlag GmbH Germany, part of Springer Nature and ESICM

Fungi and especially Candida spp. are responsible for around $20 \%$ of all microbiologically documented infections in the intensive care unit (ICU), and the incidence of invasive fungal infections (IFI) has increased steadily [1]. As reported recently, 28-day crude mortality rates remain high in those patients, around 40\% [2]. Delayed antifungal therapy (AFT) is associated with significant increase in hospital mortality and health care costs and is mainly linked to late diagnosis [3, 4]. Accordingly, blood cultures are positive in only $50-70 \%$ of cases of candidemia and time to positivity is longer than in bacteremia [2]. As a result, empirical AFT is broadly used in the ICU. However, despite efforts aiming at improving AFT management, we should admit that we still fail to target the right patients. Actually, although recommended by recent guidelines, the broadly applied risk factors based approach (i.e., disease severity, previous use of antibiotics, total parenteral nutrition, recent digestive surgery and Candida colonization) leads to AFT administration to patients in whom IFI remains unproven in up to $80 \%$ of the cases [5-7]. In addition, such a liberal strategy was shown to be ineffective regarding patients' outcome: a recent double blinded randomized controlled trial (RCT) showed that empirical treatment of critically ill patients with ICU-acquired sepsis, Candida colonization and multiple organ failure with micafungin, compared with placebo, did not increase fungal infection-free survival at day 28 [8].

In contrast, the negative consequences of the overuse of AFT on fungal ecology and resistance development

\footnotetext{
*Correspondence: jarturpaiva@gmail.com

${ }^{1}$ Department of Emergency and Intensive Care, Centro Hospitalar São Joao, Faculdade de Medicina, Universidade do Porto, Porto, Portugal Full author information is available at the end of the article
}

are well established and somewhat worrisome. Thus, Ferreira et al. showed that a policy of Candida colonization-based AFT prescriptions generated a significant change in acquired colonization patterns, especially with C. glabrata and C. parapsilosis, without any impact on candidemia incidence and on Candida-related mortality [5]. Vallabhaneni et al. showed that prior echinocandin exposure is the main risk factor for C. glabrata echinocandin nonsusceptibility and presence of FKS mutations [9]. Finally, Jensen et al. demonstrated that patients exposed to azoles for more than 7 days had a significantly larger proportion of species intrinsically less susceptible to azoles (particularly C. glabrata) among oral isolates than among initial blood isolates and that acquired resistance to fluconazole and anidulafungin was common in $C$. glabrata isolates from patients exposed to either azoles or echinocandins, suggesting that colonizing mucosal microbiota may be an unrecognized reservoir of resistant Candida species, especially C. glabrata, following treatment for candidemia [10].

As recommended for other antimicrobial agents, promoting AFT stewardship policies in the ICU is therefore mandatory. In non-neutropenic critically ill adult patients with proven or suspected invasive candidiasis, antifungal de-escalation, defined as either a switch from initial antifungal drugs (except fluconazole) to fluconazole or termination of initial AFT within 5 days following SAT initiation, may be safely performed in stabilized patients with negative blood cultures, on the basis of clinical assessment and mycological data and this strategy leads to a decrease in antifungal consumption without apparent deleterious effect on day-28 mortality $[7,11]$.

Interestingly, the serial use of biomarkers, such as procalcitonin (PCT), has been shown to allow safe antibiotic exposure reduction in critically ill patients with

\section{实


suspected or proven bacterial infections [12]. Using repeated low or decreasing PCT values as a way to stop antibiotics in patients with shock is recommended by the last Surviving Sepsis Campaign guidelines [13]. It is, however, established that PCT is not relevant for the purpose in the setting of IFI [14]. Therefore, the use of single or combined Candida-related biomarkers, such as ( $1 \rightarrow 3)$ - $\beta$-D-glucan (BDG), mannan antigen (mannan- $\mathrm{Ag}$ ) and anti-mannan antibodies (mannan- $\mathrm{Ab}$ ) have received increasing attention. In fact, biomarker-guided pre-emptive therapy with echinocandins triggered by elevated serum BDG could reduce the incidence of proven disease and might be helpful in selecting the patients that would be most likely to benefit from AFT [15]. Alternatively, one retrospective study emphasized the high negative predictive value of BDG, which could be used to safely stop empirical AFT [16]. Ideally, empirical therapy should only be prescribed for patients with severe acute septic syndromes, in which fungal etiology is likely. This is the case of patients with septic shock due to a longterm central vein catheter or intra-abdominal health care associated infection and with underlying risk factors for invasive candidiasis. This restricted policy of empirical AFT should coexist with the adoption of automated molecular tests and biomarker measurement to allow early IFI diagnosis.

In a recent issue of Intensive Care Medicine, Rouzé et al. [17] reported the results of the first RCT evaluating the impact of a complex algorithm based on serial levels of BDG, mannan-Ag and mannan-Ab measured at different time-points. The proposed decision tree is based on the respective predictive values of each biomarker according to previously published data and unpublished data from their group. Thus, mannan-Ag value was considered to yield high positive predictive value (PPV), and, as a result, any elevation of this biomarker drove antifungals continuation. In contrast, the recommendation was to stop AFT in the patients with low levels of BDG (i.e., $\leq 80 \mathrm{ng} / \mathrm{mL}$ ) at day 0 or day 4 , given its high negative predictive value (NPV). However, rising anti-mannan$\mathrm{Ab}$ levels were considered as being associated with a high risk of IFI (high-expected PPV), leading thereby to AFT continuation regardless of the BDG values. The authors show that empirical AFT could be safely stopped, without increasing risk of subsequent IFI and of death, if their rules were applied, allowing a significant reduction of treatment duration. Basically, it is worth noting that consistent data assessing those biomarkers are still lacking in the ICU setting (Table 1). One could argue that they put the cart before the horse, but such a pragmatic approach is somewhat attractive.

Those findings should, however, be considered cautiously. First, although AFT was prescribed in accordance with the most recent guidelines, one should admit that such a liberal policy is questionable given the low risk population thus targeted (i.e., less than $10 \%$ of IFI) [6]. In other words, more stringent inclusion criteria may have led to a more restricted use of AFT, blunting thereby the AFT duration shortening resulting from the compliance to the proposed decision tree. Accordingly, a multicenter study is required. Another limitation to the generalization of the results of the study is the availability of the biomarkers' measurement in daily practice.

Actually, one French large observational study including 835 patients from 87 ICUs with suspected or proven invasive candidiasis (i.e., the Amarcand2 study) showed that BDG measurement was performed in less than $4 \%$ of the cases [7]. Therefore, both cost and technical issues make any improvement still unlikely.

However, the findings presented by Rouzé et al. highlight the fact that physicians need additional tools and strategies, such as those biomarkers-based, to facilitate AFT withdrawal after empirical use in situations that had presented with high likelihood of being caused by fungi or to withhold AFT use in cases less likely to be caused by fungi. Further studies are clearly needed to define the

Table 1 Available biomarkers useful for the diagnosis of invasive candidiasis and their respective sensitivity (Se), specificity (Sp), positive predictive value (PPV) and negative predictive value (NPV) in critically ill patients

\begin{tabular}{|c|c|c|c|c|}
\hline & Se & Sp & PPV & NPV \\
\hline$\beta$-D-glucan & $\begin{array}{l}97.1 \%[\mathrm{a}] 92.9 \%[\mathrm{~b}] \mathrm{81.5} \%[\mathrm{c}] \\
\quad 76.7 \%[\mathrm{~d}] 51.6 \%[\mathrm{e}]\end{array}$ & $\begin{array}{l}30.6 \%[\mathrm{a}] 93.7 \%[\mathrm{~b}] \mathrm{82.9 \%}[\mathrm{c}] \\
57.2 \%[\mathrm{~d}] \mathbf{8 6 . 9} \%[\mathrm{e}]\end{array}$ & $\begin{array}{l}72.2 \%[\mathrm{~b}] 59.3 \%[\mathrm{e}] 19.0 \%[\mathrm{f}] \\
\quad 49.0 \%[\mathrm{~g}] 62.8 \%[\mathrm{c}] 21.7 \%[\mathrm{~d}] \\
59.3 \%[\mathrm{e}]\end{array}$ & $\begin{array}{l}98.7 \%[\mathrm{~b}] \text { 83.0\% [e] 93.2\% [f] } \\
\text { 77.0\% [g] 92.6\% [c] 94.1\% } \\
\text { [d] 83.0\% [e] }\end{array}$ \\
\hline Mannan-Ag & $32.3 \%[\mathrm{a}] 43.3 \%[\mathrm{~d}] 64.3 \%[\mathrm{~h}]$ & $95.8 \%[\mathrm{a}] 67.3 \%$ [d] 95.7\% [h] & $16.7 \%[4] 90.0 \%[h]$ & $88.7 \%[4] 81.8 \%[h]$ \\
\hline Mannan-Ab & $52.9 \%[1] 25.8 \%[\mathrm{~d}] 61.5 \%[\mathrm{~h}]$ & $66.2 \%[1] 89.0 \%[\mathrm{~d}] 65.8 \%[\mathrm{~h}]$ & $26.7 \%[4] 55.2 \%[\mathrm{~h}]$ & $88.6 \%[4] 71.4 \%[\mathrm{~h}]$ \\
\hline Mannan-Ag + Ab & $58.8 \%$ [1] 54.8\% [d] 86.2\% [h] & $64.8 \%[1] 78.7 \%[\mathrm{~d}] 60.5 \%[\mathrm{~h}]$ & $17.3 \%[4] 62.5 \%[h]$ & $89.6 \%[4] 85.2 \%[h]$ \\
\hline CATGA & $53.3 \%$ [4] 71.0\% [e] 58.1\% [h] & $64.3 \%$ [4] 57.3\% [e] 92.0\% [h] & $18.4 \%$ [4] 38.6\% [e] 81.8\% [h] & $90.1 \%[4] 83.9 \%[\mathrm{e}] 78.0 \%[\mathrm{~h}]$ \\
\hline
\end{tabular}

(a) Poissy J et al. (2014). Critical care 18:R135; (b) Posteraro B et al. (2011). Critical Care 15:R249; (c) Fortun J et al. (2014). J Antimicrob Chemother 69:3134-3141; (d) Leon C et al. (2016). Crit Care 20:149; (e) Leon C et al. (2012). Intensive care medicine 38:1315-1325; (f) Martin-Mazuelos E et al. (2015). Intensive Care Med 41:14241432; (g) Tissot F et al. (2013). Am J Respirat Crit Care Med; (h) Martinez-Jimenez MC et al. (2015). J Antimicrob Chemother 70:2354-2361 
populations in which serial measurement of fungal biomarkers should be performed (1) for early withdrawal of empirically started AFT and (2) for early detection of IFI and decision on who to put on preemptive AFT. A study employing serial measurement of one effective biomarker, such as BDG, using its changes to guide preemptive initiation of AFT but in a preselected high clinical risk population (such as those with pancreatitis or those submitted to major abdominal surgery) so as to decrease the number of patients unnecessarily exposed to AFT could be an excellent next step. Such a policy could allow AFT sparing and a better allocation of AFT, with consequent improved outcomes, cost savings and the avoided ecological damages.

\section{Author details}

${ }^{1}$ Department of Emergency and Intensive Care, Centro Hospitalar São Joao, Faculdade de Medicina, Universidade do Porto, Porto, Portugal. ${ }^{2}$ Grupo de Infeçao e Sépsis, Porto, Portugal. ${ }^{3}$ Service de Médecine Intensive Réanimation, Hôpital François Mitterrand, CHU Dijon, Dijon, France.

\section{Compliance with ethical standards}

\section{Conflicts of interest}

José-Artur Paiva: no conflicts of interest. Pierre-Emmanuel Charles: received speaking fees from Astellas and Merck; and received a research grant from Merck.

Received: 24 September 2017 Accepted: 31 October 2017 Published online: 8 November 2017

\section{References}

1. Vincent JL, Rello J, Marshall J, Silva E, Anzueto A, Martin CD, Moreno R, Lipman J, Gomersall C, Sakr Y, Reinhart K (2009) International study of the prevalence and outcomes of infection in intensive care units. JAMA 302:2323-2329

2. Paiva JA, Pereira JM, Tabah A, Mikstacki A, de Carvalho FB, Koulenti $D$, Ruckly S, Cakar N, Misset B, Dimopoulos G, Antonelli M, Rello J, Ma X, Tamowicz B, Timsit JF (2016) Characteristics and risk factors for 28-day mortality of hospital acquired fungemias in ICUs: data from the EUROBACT study. Crit Care 20:53

3. Bassetti M, Garnacho-Montero J, Calandra T, Kullberg B, Dimopoulos G, Azoulay E, Chakrabarti A, Kett D, Leon C, Ostrosky-Zeichner L, Sanguinetti M, Timsit JF, Richardson MD, Shorr A, Cornely OA (2017) Intensive care medicine research agenda on invasive fungal infection in critically il patients. Intensive Care Med. https://doi.org/10.1007/s00134-017-4731-2

4. Kollef M, Micek S, Hampton N, Doherty JA, Kumar A (2012) Septic shock attributed to Candida infection: importance of empiric therapy and source control. Clin Infect Dis 54:1739-1746

5. Ferreira D, Grenouillet F, Blasco G, Samain E, Henon T, Dussaucy A, Millon L, Mercier M, Pili-Floury S (2015) Outcomes associated with routine systemic antifungal therapy in critically ill patients with Candida colonization. Intensive Care Med 41:1077-1088

6. Pappas PG, Kauffman CA, Andes DR, Clancy CJ, Marr KA, Ostrosky-Zeichner L, Reboli AC, Schuster MG, Vazquez JA, Walsh TJ, Zaoutis TE, Sobel JD (2016) Clinical practice guideline for the management of Candidiasis: 2016 update by the Infectious Diseases Society of America. Clin Infect Dis 62:e1-e50
7. Leroy O, Bailly S, Gangneux JP, Mira JP, Devos P et al (2016) Systemic antifungal therapy for proven or suspected invasive candidiasis: the AmarCAND 2 study. Ann Intensive Care 6:2

8. Timsit JF, Azoulay E, Schwebel C, Charles PE, Cornet M et al (2016) Empirical Micafungin treatment and survival without invasive fungal infection in adults with ICU-acquired sepsis, Candida colonization, and multiple organ failure: the EMPIRICUS Randomized Clinical Trial. JAMA 316:1555-1564

9. Vallabhaneni S, Cleveland AA, Farley MM, Harrison LH, Schaffner W, Beldavs ZG, Derado G, Pham CD, Lockhart SR, Smith RM, (2015). Epidemiology and risk factors for echinocandin nonsusceptible Candida glabrata bloodstream infections: data from a large multisite population-based Candidemia surveillance program, 2008-2014. Open Forum Infect Dis 2: ofv163

10. Jensen $\mathrm{RH}$, Johansen HK, Søes LM, Lemming LE et al (2016) Posttreatment antifungal resistance among colonizing Candida isolates in Candidemia patients: results from a Systematic Multicenter Study. Antimicrob Agents Chemoth 60:1500-1508

11. Bailly S, Leroy O, Montravers P, Constantin JM, Dupont H et al (2015) Antifungal de-escalation was not associated with adverse outcome in critically ill patients treated for invasive candidiasis: post hoc analyses of the AmarCAND2 study data. Intensive Care Med 41:1931-1940

12. de Jong $E$, van Oers JA, Beishuizen A, Vos P, Vermeijden WJ, Haas LE, Loef BG, Dormans T, van Melsen GC, Kluiters YC, Kemperman H, van den Elsen MJ, Schouten JA, Streefkerk JO, Krabbe HG, Kieft H, Kluge GH, van Dam VC, van Pelt J, Bormans L, Otten MB, Reidinga AC, Endeman H, Twisk JW, van de Garde EMW, de Smet AMGA, Kesecioglu J, Girbes AR, Nijsten MW, de Lange DW (2016) Efficacy and safety of procalcitonin guidance in reducing the duration of antibiotic treatment in critically ill patients: a randomised, controlled, open-label trial. Lancet Infect Dis 16(7):819-827

13. Rhodes A, Evans LE, Alhazzani W, Levy MM, Antonelli M, Ferrer R, Kumar A, Sevransky JE, Sprung CL, Nunnally ME, Rochwerg B, Rubenfeld GD, Angus DC, Annane D, Beale RJ, Bellinghan GJ, Bernard GR, Chiche JD, Coopersmith C, De Backer DP, French CJ, Fujishima S, Gerlach H, Hidalgo JL, Hollenberg SM, Jones AE, Karnad DR, Kleinpell RM, Koh Y, Lisboa TC, Machado FR, Marini JJ, Marshall JC, Mazuski JE, Mclntyre LA, McLean AS, Mehta S, Moreno RP, Myburgh J, Navalesi P, Nishida O, Osborn TM, Perner A, Plunkett CM, Ranieri M, Schorr CA, Seckel MA, Seymour CW, Shieh L, Shukri KA, Simpson SQ, Singer M, Thompson BT, Townsend SR, Van der Poll T, Vincent JL, Wiersinga WJ, Zimmerman JL, Dellinger RP (2017) Surviving sepsis Campaign: international Guidelines for management of sepsis and septic shock: 2016. Intensive Care Med 43:304-377

14. Charles PE, Kus E, Aho S, Prin S, Doise JM, Olsson NO, Blettery B, Quenot JP (2009) Serum procalcitonin for the early recognition of nosocomial infection in the critically ill patients: a preliminary report. BMC Infect Dis $9: 49$

15. Ostrosky-Zeichner L, Shoham S, Vazquez J, Reboli A, Betts R, Barron MA, Schuster M, Judson MA, Revankar SG, Caeiro JP, Mangino JE, Mushatt D, Bedimo R, Freifeld A, Nguyen MH, Kauffman CA, Dismukes WE, Westfall AO, Deerman JB, Wood C, Sobel JD, Pappas PG (2014) MSG-01: a randomized, double-blind, placebo-controlled trial of caspofungin prophylaxis followed by preemptive therapy for invasive candidiasis in high-risk adults in the critical care setting. Clin Infect Dis 58:1219-1226

16. Nucci M, Nouer SA, Esteves P, Guimaraes T, Breda G, de Miranda BG, Queiroz-Telles F, Colombo AL (2016) Discontinuation of empirical antifungal therapy in ICU patients using 1,3-beta-d-glucan. J Antimicrob Chemother 71:2628-2633

17. Rouzé A, Loridant S, Poissy J, Dervaux B, Sendid B, Cornu M, Nseir S, S-TAFE study group (2017) Biomarker-based strategy for early discontinuation of empirical antifungal treatment in critically ill patients: a randomized controlled trial. Intensive Care Med 43:1668-1677. https:// doi.org/10.1007/s00134-017-4932-8 